\title{
Prediction of 10 Years and Lifetime Atherosclerotic Cardiovascular Disease (ASCVD) Risk Among Working Physician of CMCH
}

\author{
ANISULAWAL ${ }^{1}$, NURUDDIN TAREQ ${ }^{1}$, BIPLOB BHATTACHARJEE ${ }^{1}$, IBRAHIM CHOWDHURY ${ }^{1}$, ASHISH DEY ${ }^{1}$, \\ PROBIR KUMAR DAS ${ }^{1}$, NORESH CHENDRA ROY, ABUL HOSSAIN SHAHIN, NURUDDIN JAHANGIR, \\ SANDIPAN DAS, SALEH UDDIN SIDDIQUE, SHAKERA AHMED ${ }^{2}$, MANZUR MURSHED ${ }^{1}$ \\ ${ }^{1}$ Department of Cardiology, Chittagong Medical College Hospital, Chittagong. ${ }^{2}$ Department of Surgery, \\ Chittagong Medical College Hospital, Chittagong \\ Address of Correspondence: Dr. Anisul Awal, Assistant Professor Cardiology, Chittagong Medical College. \\ Email: anisul.awal@yahoo.com
}

\begin{abstract}
Background:Cardiovascular diseases (CVD) still represent the leading cause of morbidity and mortality, worldwide. As, physicians have a vital role in battling the CVD epidemic by counseling and motivating people to reduce their risk, they should also set an example by taking care of their own health.

Objective: To estimate the CVD risk factors prevalence and predict 10 years \& lifetime atherosclerotic CVD (ASCVD) risk among physician.

Method: Data was collected for this cross-sectional study from 137 working physicians of Chittagong Medical College Hospital on $17^{\text {th }}$ January, 2017. The participants filled a structured questionnaire followed by physical and biochemical measurements including BMI, blood pressure, waist circumference, lipid profile, and fasting blood glucose. We estimated the 10-year predicted risk for ASCVD events (myocardial infarction, coronary insufficiency, atherothrombotic stroke, or CVD death) for the physicians $>40$ years of age and lifetime predicted risk for ASCVD was estimated for all physicians irrespective of age.

Result: Most of the physician irrespective of sex had high lifetime predicted risk of ASCVD (68.4\% female, $77.8 \%$ male \& $75.2 \%$ total, P>0.05). Regarding 10-year predicted risk of ASCVD among the physician $>40$ years of age $24.0 \%$ female and $40.6 \%$ male physician had moderate to high risk. The following overall prevalence rates of risk factors were reported: current smoker $6.7 \%$, obesity $86.1 \%$, reported hypertension $21.1 \%$ and DM was 11.9\%. The prevalence of total cholesterol levels e"200 gm/dl was $49.6 \%$ and LDL levels $>130 \mathrm{mg} / \mathrm{dl}$ 46.7\% , HDL levels (d"40 mg/dl) was $64.2 \%$ and high fasting blood glucose ( $>126 \mathrm{mg} / \mathrm{dl}$ ) was 27.7\%. The majority of the participants (61.31\%) had $>3$ risk factors. Only 14.59\% had either no or less than 3 CVD risk factors.

Conclusions: Prevalence CVD risk factors were high among working physicians and most of them had high lifetime or 10 years predicted risk for ASCVD events.
\end{abstract}

Background: Cardiovascular diseases (CVD) still represent the leading cause of morbidity and mortality, worldwide.

The burden of cardiovascular diseases (CVDs) is rising in developing countries, particularly low and middle income countries (LMICs), creating a major challenge for the health sector. According to the World Health Organization (WHO) CVDs were the cause of 17.5 million deaths (31\% of all death) around the world in 2012 , of which $80 \%$ occurred in $\mathrm{LMICs}^{1}$, and $85 \%$ of all global disability arose from CVDs. ${ }^{2}$

CVDs and its associated known risk factors account for $13.4 \%$ of disability adjusted life years (DALYs) lost in
Bangladesh. ${ }^{3}$ The major CVD risk factors such as abnormal glucose metabolism, high blood pressure, dyslipidemia, smoking, along with increasing age are well established. ${ }^{2,4}$ Obesity constitutes major risks for CVDs both directly (through underlying insulin resistance and inflammatory changes) and indirectly (through the effect on other immediate risk factors like T2DM, dyslipidemia and HTN). After China and India, Bangladesh has the highest prevalence of diabetes mellitus (DM) among LMICs (8.4 million or $10 \%$ of the population) and the prevalence could increase by $13 \%$ by $2030 .{ }^{5}$ According to the INTERHEART study Bangladeshis had the highest prevalence of CVD risk factors among five South Asian countries with the prevalence of self-reported history 
of hypertension (14.3\%), abdominal obesity (43.3\%), current and former smoking (59.9\%), and the lowest prevalence for regular physical activity $(1.3 \%)$ and daily intake of fruits and vegetables (8.6\%). ${ }^{6}$ In Bangladesh, $99.6 \%$ male and $97.9 \%$ females are exposed to at least one of the established risks of CVDs and at risk of CVD at a younger age (below 40 years in men). ${ }^{3,7}$

Health professionals such as physicians, nurses, midwives, pharmacists, dentists, physiologists, and other healthrelated professionals have an enormous potential to play a key role in battling the CVD risk factors epidemic. They can play this role as role model, clinician, educator, and scientist.In community and clinical settings, health professionals are the most Knowledgeable in health matters and they are expected to act on the basis of this knowledge. In their society and their communities they are expected to be role models for the rest of the population. And that includes, in general, their behaviour in health-related matters such as diet and exercise, and particularly regarding tobacco. Professionally respected and popularly revered, they could use such clout to change current smoking trends and other unhealthy lifestyles.Research has shown that health professionals who are smokers are less likely to promote smoking cessation or engage in tobacco control.This statement is applicable for other risk factors ${ }^{8}$.

Since physicians are one decisive factor in any health strategies employed they should also set an example by taking care of their own health. Thus the aim of our study was primary prevention of cardiovascular diseases among physicians, with the following objective; to determine the CVD risk factors prevalence and to predict 10 years \& lifetime atherosclerotic CVD (ASCVD) risk among working physician of Chittagong Medical College \& Hospital, Chittagong, Bangladesh.

\section{Materials and Methods}

It was a hospital based cross-sectional study, conducted among all available working physicians attending in a morning academic session on $17^{\text {th }}$ January 2017 in Chittagong Medical College and Hospital.Tools of the study:

A. A structured questionnaire that included;

1) Socio-demographic characteristics: age, sex,

2) Present history of hypertension, diabetes mellitus with medication history

3) Lifestyle habits e.g. smoking habit.

B. Clinical examination;

1) Weight and height were recorded by validated scale; also waist circumference was measured by measuring tape. Body mass index (BMI) - the formula established by Quetelet $(\mathrm{BMI}=$ weight in $\mathrm{kg} /$ height in $\mathrm{m} 2$ ) was used. According to WHO criteria (For Asian)

- $\quad$ Normal BMI 18.5-22.9 kg/m2

- Overweight e"23 kg/m2

- $\quad$ Obese $\geq 25 \mathrm{~kg} / \mathrm{m} 2$

2) Blood pressure (BP) was measured by awellcalibrated mercury sphygmomanometer machine. Measurements were taken in the right upper limb, after 5 minutes of rest, with the subject seated and the arm supported. Blood pressure was measured twice with a two-minute interval between them. For data analysis purposes, the second blood pressure measurement was taken into account, and hypertension was defined by values greater than or equal to $140 / 90 \mathrm{mmHg}$ or use of anti-hypertensive.

3) Waist circumference (WC) was measured at the midpoint between the last rib and the iliac crest, at the end of expiration, with a measuring tape graduated in centimeters.

\section{Waist/height ratio measured as waist circumference /height.}

- Value of $\geq 0.5$ willbe taken as centrally obese.

- Value of $<0.5$ as normal.

C. Laboratory Investigations:

1) Lipid profile (total cholesterol level, triglycerides, high density lipoprotein cholesterol (HDL-C), low density lipoprotein cholesterol (LDL-C) presence of dyslipidemia if

- Cholesterol $\geq 200 \mathrm{mg} / \mathrm{dL}$,

- $\mathrm{HDL}-\mathrm{C}<40 \mathrm{mg} / \mathrm{dL}$,

- $\quad$ LDL-C $\geq 130 \mathrm{mg} / \mathrm{dL}$,

- Triglycerides $\geq 150 \mathrm{mg} / \mathrm{dL}$ )

2) Fasting blood sugar (FBS); diabetes mellitus can be diagnosed if known to be diabetic/fasting $\geq 7 \mathrm{mmol} / \mathrm{L}$ ).

We estimated the 10-year predicted risk for ASCVD events (myocardial infarction or coronary death, and fatal or non-fatal stroke) using the new Pooled Cohort Equations for the physicians $>40$ years of age. These allowed us to stratify the study samples into 2 groups:

1. Those with low predicted 10-year risk (10-year risk $<7.5 \%$ ) and

2. Those with high predicted 10 -year risk (10-year risk $\geq 7.5 \%$ ). 
The lifetime predicted risk for ASCVD (myocardial infarction, coronary insufficiency, angina, atherothrombotic stroke, intermittent claudication, or CVD death) was estimated for all physicians irrespective of age using a previously published algorithm based on the aggregate risk factor burden. This method of classification resulted in the formation of 2 lifetime risk different groups:

1. Low $(<39 \%)$ lifetime and

2. High (e"39\%) lifetime predicted risk.

Data were analyzed by SPSS version-23 on computer. Categorical variables were expressed as frequency and percentage. Continuous variables were expressed as mean and SD. Comparison of the ASCVD risk category between male and female physicians was assessed by Chi-square test. Statistical significance will be defined as $\mathrm{P}<0.05$.

\section{Results:}

The following overall prevalence rates of risk factors were reported: current smoker $6.7 \%$, overweight and obesity $86.1 \%$ and reported hypertension $21.1 \%$ (included both those who were on and not on treatments), with an estimated prevalence of $19 \%$ for measured systolic blood pressure $\geq 140 \mathrm{mmHg}$ and $23.4 \%$ for diastolic blood pressure $\geq 90 \mathrm{mmHg}$. The prevalence of total cholesterol levels $\geq 200 \mathrm{gm} / \mathrm{dl}$ was $49.6 \%$ and LDL levels $>130 \mathrm{mg} / \mathrm{dl} 46.7 \%$. Prevalence of HDL levels $(\leq$ $40 \mathrm{mg} / \mathrm{dl}$ ) was $64.2 \%$. The low HDL level ( $\leq 40 \mathrm{mg} / \mathrm{dl})$ among males was $64.1 \%$, while it was $26.6 \%$ among females. Reported DM was $11.9 \%$ with an overall prevalence of $27.7 \%$ for fasting blood sugar $>126 \mathrm{mg} /$ dl. The majority of the participants $(61.31 \%)$ had $>3$ risk factors. Only $14.59 \%$ had either no or less than 3 CVD risk factors.

Most of the physician irrespective of sex had high lifetime predicted risk of ASCVD (68.4\% female, $77.8 \%$ male \& 75.2\% total, $\mathrm{P}>0.05)$. Regarding 10-year predicted risk of ASCVD among the physician $>40$ years of age $24.0 \%$ female and $40.6 \%$ male physician had moderate to high risk.

Table-I

General characteristics of the study population $(n=137)$

\begin{tabular}{|c|c|c|}
\hline Variables & $\mathrm{n}$ & $\%$ \\
\hline \multicolumn{3}{|l|}{ Sex } \\
\hline Male & 99 & 72.3 \\
\hline Female & 38 & 27.7 \\
\hline \multicolumn{3}{|l|}{ Age } \\
\hline$<40$ years & 47 & 34.3 \\
\hline$\geq 40$ years & 90 & 65.7 \\
\hline \multicolumn{3}{|l|}{ Current smoker } \\
\hline Yes & 12 & 8.76 \\
\hline No & 125 & 91.24 \\
\hline \multicolumn{3}{|l|}{ Reported hypertension } \\
\hline Yes & 32 & 23.36 \\
\hline No & 105 & 76.64 \\
\hline \multicolumn{3}{|l|}{ Reported diabetes } \\
\hline Yes & 19 & 13.87 \\
\hline No & 118 & 86.13 \\
\hline Anthropometric, clinical \& laboratory measurements & Mean & $\pm \mathrm{SD}$ \\
\hline Age, in years & 43.09 & 8.58 \\
\hline Body mass index $\left(\mathrm{kg} / \mathrm{m}^{2}\right)$ & 25.82 & 4.03 \\
\hline Waist height ratio & 0.55 & 0.045 \\
\hline Systolic blood pressure (mm of $\mathrm{Hg}$ ) & 124.33 & 13.94 \\
\hline Diastolic blood pressure (mm of $\mathrm{Hg}$ ) & 81.77 & 8.31 \\
\hline Total cholesterol $(\mathrm{mg} / \mathrm{dl})$ & 204.20 & 42.95 \\
\hline Triglyceride $(\mathrm{mg} / \mathrm{dl})$ & 181.98 & 96.44 \\
\hline HDL cholesterol (mg/dl) & 37.63 & 6.05 \\
\hline LDL cholesterol (mg/dl) & 129.69 & 30.74 \\
\hline Fasting blood glucose $(\mathrm{mmol} / \mathrm{L})$ & 6.83 & 2.54 \\
\hline
\end{tabular}


Table-II

Proportion of cardiovascular diseases risk factors among the study population by gender

\begin{tabular}{|c|c|c|c|c|c|c|c|}
\hline \multirow[t]{2}{*}{ Variables } & & \multicolumn{2}{|c|}{ Total } & \multicolumn{2}{|c|}{ Male } & \multicolumn{2}{|c|}{ Female } \\
\hline & & $\mathrm{N}$ & $\%$ & $\mathrm{n}$ & $\%$ & $\mathrm{n}$ & $\%$ \\
\hline \multirow[t]{2}{*}{ Smoking habit } & Smoker & 12 & 8.76 & 12 & 12.12 & 0 & 0 \\
\hline & Non-smoker & 125 & 91.24 & 87 & 87.88 & 38 & 100 \\
\hline \multirow[t]{3}{*}{ BMI } & $\leq 22.9 \mathrm{~kg} / \mathrm{m}^{2}$ & 19 & 13.9 & 14 & 14.1 & 5 & 13.2 \\
\hline & $23-24.9 \mathrm{~kg} / \mathrm{m}^{2}$ & 38 & 27.7 & 27 & 27.3 & 11 & 28.9 \\
\hline & $\geq 25 \mathrm{~kg} / \mathrm{m}^{2}$ & 80 & 58.4 & 58 & 58.6 & 22 & 57.9 \\
\hline \multirow[t]{2}{*}{ Waist height ratio } & $<0.5$ & 16 & 11.7 & 13 & 13.1 & 3 & 7.9 \\
\hline & $\geq 0.5$ & 121 & 88.3 & 86 & 86.9 & 35 & 92.1 \\
\hline \multirow[t]{2}{*}{ FBG } & $<7 \mathrm{mmol} / \mathrm{L}$ & 99 & 72.3 & 71 & 71.7 & 28 & 73.7 \\
\hline & $\geq 7 \mathrm{mmol} / \mathrm{L}$ & 38 & 27.7 & 28 & 28.3 & 10 & 26.3 \\
\hline \multirow[t]{2}{*}{ Cholesterol } & $<200 \mathrm{mg} / \mathrm{dl}$ & 69 & 50.4 & 47 & 47.5 & 22 & 57.9 \\
\hline & $\geq 200 \mathrm{mg} / \mathrm{dl}$ & 68 & 49.6 & 52 & 52.5 & 16 & 42.1 \\
\hline \multirow[t]{2}{*}{ Triglyceride } & $<150 \mathrm{mg} / \mathrm{dl}$ & 87 & 63.5 & 58 & 58.6 & 29 & 76.3 \\
\hline & $\geq 150 \mathrm{mg} / \mathrm{dl}$ & 50 & 36.5 & 41 & 41.4 & 9 & 23.7 \\
\hline \multirow[t]{2}{*}{ LDL } & $<130 \mathrm{mg} / \mathrm{dl}$ & 73 & 53.3 & 48 & 48.5 & 25 & 65.8 \\
\hline & $\geq 130 \mathrm{mg} / \mathrm{dl}$ & 64 & 46.7 & 51 & 51.5 & 13 & 34.2 \\
\hline \multirow[t]{2}{*}{ HDL } & $\geq 40 \mathrm{mg} / \mathrm{dl}$ & 49 & 35.8 & 30 & 30.3 & 19 & 50.0 \\
\hline & $<40 \mathrm{mg} / \mathrm{dl}$ & 88 & 64.2 & 69 & 67.7 & 19 & 50.0 \\
\hline
\end{tabular}

Table-III

Overall and age-stratified prevalence (\%) of risk factors

\begin{tabular}{|c|c|c|c|c|c|c|c|}
\hline \multirow[t]{2}{*}{ Variables } & & \multicolumn{2}{|c|}{ Total } & \multicolumn{2}{|c|}{$<40$ years } & \multicolumn{2}{|c|}{$\geq 40$ years } \\
\hline & & $\mathrm{N}$ & $\%$ & $\mathrm{n}$ & $\%$ & $\mathrm{n}$ & $\%$ \\
\hline \multirow[t]{2}{*}{ Smoking habit } & Smoker & 12 & 8.76 & 3 & 4.5 & 9 & 7.8 \\
\hline & Non-smoker & 125 & 91.24 & 42 & 95.5 & 83 & 92.2 \\
\hline \multirow[t]{3}{*}{ BMI } & $\leq 22.9 \mathrm{~kg} / \mathrm{m}^{2}$ & 19 & 13.9 & 8 & 17.0 & 11 & 12.2 \\
\hline & $23-24.9 \mathrm{~kg} / \mathrm{m}^{2}$ & 38 & 27.7 & 13 & 27.3 & 25 & 27.8 \\
\hline & $\geq 25 \mathrm{~kg} / \mathrm{m}^{2}$ & 80 & 58.4 & 26 & 53.7 & 54 & 60.0 \\
\hline \multirow[t]{2}{*}{ Waist height ratio } & $<0.5$ & 16 & 11.7 & 7 & 14.5 & 9 & 10.0 \\
\hline & $\geq 0.5$ & 121 & 88.3 & 40 & 85.5 & 81 & 90.0 \\
\hline \multirow[t]{2}{*}{ FBG } & $<7 \mathrm{mmol} / \mathrm{L}$ & 99 & 72.3 & 42 & 89.4 & 57 & 63.3 \\
\hline & $\geq 7 \mathrm{mmol} / \mathrm{L}$ & 38 & 27.7 & 5 & 10.6 & 53 & 36.7 \\
\hline \multirow[t]{2}{*}{ Cholesterol } & $<200 \mathrm{mg} / \mathrm{dl}$ & 69 & 50.4 & 24 & 51.1 & 45 & 50.0 \\
\hline & $\geq 7200 \mathrm{mg} / \mathrm{dl}$ & 68 & 49.6 & 23 & 48.9 & 45 & 50.0 \\
\hline \multirow[t]{2}{*}{ Triglyceride } & $<150 \mathrm{mg} / \mathrm{dl}$ & 87 & 63.5 & 42 & 95.5 & 83 & 92.2 \\
\hline & $\geq 150 \mathrm{mg} / \mathrm{dl}$ & 50 & 36.5 & 2 & 4.5 & 7 & 7.8 \\
\hline \multirow[t]{2}{*}{ LDL } & $<130 \mathrm{mg} / \mathrm{dl}$ & 73 & 53.3 & 26 & 55.3 & 47 & 52.2 \\
\hline & $\geq 130 \mathrm{mg} / \mathrm{dl}$ & 64 & 46.7 & 23 & 44.7 & 43 & 47.8 \\
\hline \multirow[t]{2}{*}{ HDL } & $\geq 40 \mathrm{mg} / \mathrm{dl}$ & 49 & 35.8 & 16 & 34.0 & 33 & 36.7 \\
\hline & $<40 \mathrm{mg} / \mathrm{dl}$ & 88 & 64.2 & 31 & 66.0 & 57 & 63.3 \\
\hline
\end{tabular}




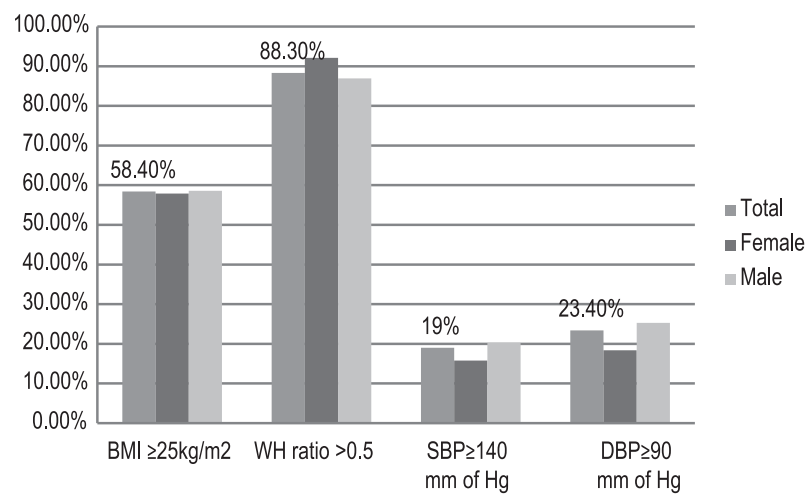

Fig.-1: Overall \& sex stratified distribution of the prevalence (\%) of risk factors

Table-IV

Clustering of CVD risk factors by gender

\begin{tabular}{|c|c|c|c|c|}
\hline \multicolumn{2}{|c|}{$\begin{array}{l}\text { Risk factors } \\
\text { (Smoking HTN, } \\
\text { DM, Cholesterol, } \\
\text { LDL, HDL, WH } \\
\text { ratio, Obesity/ } \\
\text { Overweight) }\end{array}$} & $\begin{array}{l}\text { Sex of th } \\
\text { Female } \\
(n=36)\end{array}$ & $\begin{array}{l}\text { hysician } \\
\text { Male } \\
(n=97)\end{array}$ & $\begin{array}{c}\text { Total } \\
(n=133)\end{array}$ \\
\hline \multirow[t]{2}{*}{0 Risk factor } & $\mathrm{N}$ & 2 & 1 & 3 \\
\hline & $\%$ & $5.6 \%$ & $1.0 \%$ & $2.3 \%$ \\
\hline \multirow[t]{2}{*}{1 Risk factor } & $\mathrm{N}$ & 0 & 2 & 2 \\
\hline & $\%$ & $0.0 \%$ & $2.1 \%$ & $1.5 \%$ \\
\hline \multirow[t]{2}{*}{2 Risk factors } & $\mathrm{N}$ & 9 & 6 & 15 \\
\hline & $\%$ & $25.0 \%$ & $6.2 \%$ & $11.3 \%$ \\
\hline \multirow[t]{2}{*}{3 Risk factors } & $\mathrm{N}$ & 7 & 26 & 33 \\
\hline & $\%$ & $19.4 \%$ & $26.8 \%$ & $24.8 \%$ \\
\hline \multirow[t]{2}{*}{4 Risk factors } & $\mathrm{N}$ & 8 & 34 & 42 \\
\hline & $\%$ & $22.2 \%$ & $35.1 \%$ & $31.6 \%$ \\
\hline \multirow[t]{2}{*}{5 Risk factors } & $\mathrm{N}$ & 10 & 22 & 32 \\
\hline & $\%$ & $27.8 \%$ & $22.7 \%$ & $24.1 \%$ \\
\hline \multirow[t]{2}{*}{6 Risk factors } & $\mathrm{N}$ & 0 & 3 & 3 \\
\hline & $\%$ & $0.0 \%$ & $3.1 \%$ & $2.3 \%$ \\
\hline \multirow[t]{2}{*}{7 Risk factors } & $\mathrm{N}$ & 0 & 3 & 3 \\
\hline & $\%$ & $0.0 \%$ & $3.1 \%$ & $2.3 \%$ \\
\hline
\end{tabular}

Table-V

ASCVD 10 years risk category of the physicians (age >40yrs) by gender

\begin{tabular}{lcccc}
\hline ASCVD 10 years & \multicolumn{4}{c}{ Sex of the physician } \\
Risk category & & Female & Male & Total \\
& & & & \\
\hline Mild ASCVD 10 Yrs & $\mathrm{n}$ & 19 & 44 & 63 \\
Risk (0-5\%) & $\%$ & $76.0 \%$ & $59.5 \%$ & $63.6 \%$ \\
Moderate ASCVD 10 & $\mathrm{n}$ & 3 & 9 & 12 \\
Yrs Risk (5-7.5\%) & $\%$ & $12.0 \%$ & $12.2 \%$ & $12.1 \%$ \\
High ASCVD 10 Yrs & $\mathrm{n}$ & 3 & 21 & 24 \\
Risk (>7.5\%) & $\%$ & $12.0 \%$ & $28.4 \%$ & $24.2 \%$ \\
\hline Total & $\mathrm{n}$ & 25 & 74 & 99 \\
\hline & & \multicolumn{4}{c}{$\mathrm{p}>0.05$} \\
\end{tabular}

Table-VI

Lifetime risk category of the physician by gender $(n=137)$

\begin{tabular}{|c|c|c|c|}
\hline \multirow{2}{*}{$\begin{array}{l}\text { Lifetime risk } \\
\text { category }\end{array}$} & \multicolumn{2}{|c|}{ Sex of the physician } & \multirow[t]{2}{*}{ Total } \\
\hline & Female & Male & \\
\hline Low life time risk $<39 \%$ n & 12 & 22 & 34 \\
\hline$\%$ & $31.6 \%$ & $22.2 \%$ & $24.8 \%$ \\
\hline High lifetime risk $>39 \% \mathrm{n}$ & 26 & 77 & 103 \\
\hline$\%$ & $68.4 \%$ & $77.8 \%$ & $75.2 \%$ \\
\hline Total & 38 & 99 & 137 \\
\hline
\end{tabular}

Table-VII

Lifetime risk category of the physician ( $<40$ years) by gender

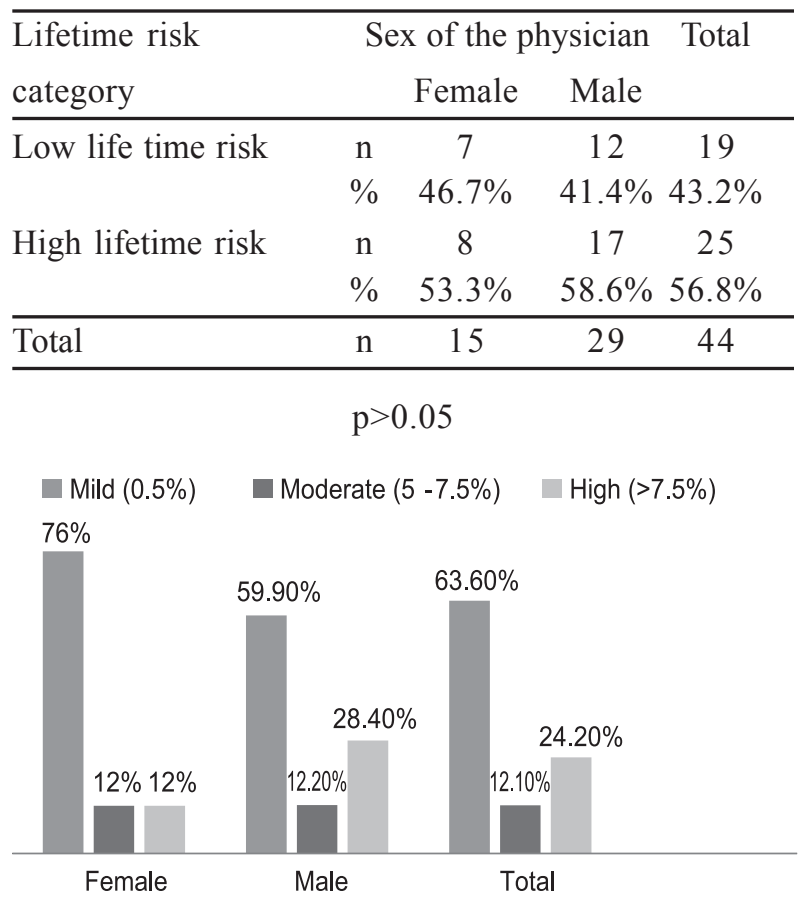

Fig.-2: ASCVD 10 years risk for >40years aged participant $(n=99)$

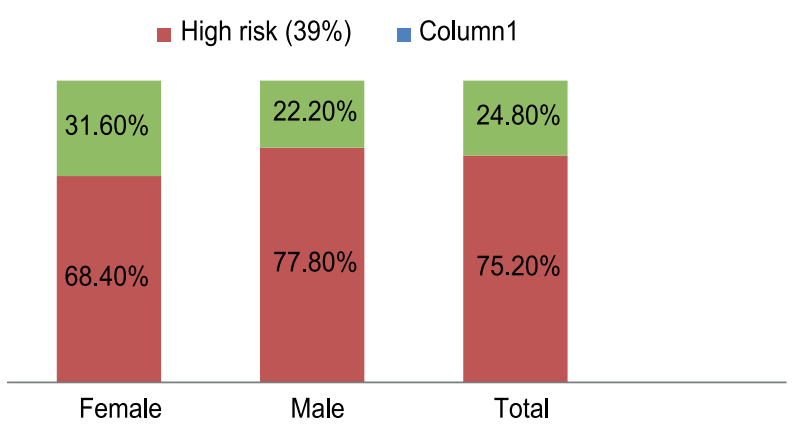

Fig.-3: Life time risk for all participant 


\section{Discussion:}

Cardiovascular diseases are very important issue for the health care system. They are usually chronic diseases widespread in the society that require costly treatment and cause long sick absenteeism and partial or total incapacity for work, therefore they constitute a medical, social and economic problem. ${ }^{9}$ In the current study, we noted a high prevalence of cardiovascular diseases risk factors, including overweight or obesity, central obesity, hypertension, diabetes mellitus, and dyslipidemia among 137 working physician of Chittagong Medical College Hospital, 2017. To our knowledge, it is the first study in Bangladesh estimating the 10 years and lifetime risk of ASCVD among physicians. Study revealed that most of the physician irrespective of sex had high lifetime predicted risk of ASCVD (68.4\% female, $77.8 \%$ male \& $75.2 \%$ total, $\mathrm{P}>0.05$ ). Regarding 10 -year predicted risk of ASCVD among the physician $>40$ years of age $24.0 \%$ female and $40.6 \%$ male physician had moderate to high risk.

Tobacco control represents a key area in which doctors can make a significant positive impact on their patients' lives. Despite this fact, however, doctors in many regions including this study are known to smoke tobacco at rates similar to or even exceeding those seen within the general population. ${ }^{10}$ Smoking is a very common avoidable risk factor for CVD. There are about one billion current smokers in the world, and the prevalence of daily smoking varied across WHO regions. ${ }^{11}$ The highest overall prevalence is estimated to be $31 \%$ in the WHO European region. ${ }^{12}$ The prevalence of current tobacco use (smoking) among the physicians in this study was lower to overall prevalence and gender distribution of smoking revealed in the national survey of NCD risk factors. Tobacco consumption is quite common in Bangladesh: prevalence is $51.0 \%$ for any form and $26.2 \%$ for smoking. ${ }^{13}$

In general population of Bangladesh, $21.5 \%$ adults (21\% male, $22 \%$ female) $\mathrm{BMI} \geq 25 \mathrm{~kg} / \mathrm{m}^{2}$; increased waist circumference is alarming, especially in women $(33.7 \%) .{ }^{13}$ Despite the fact that physicians are healthier and have better health habits than general population, our findings are surprising, as the current study revealed high frequency $(58.4 \%)$ of excess body weight (BMI $>25 \mathrm{~kg}$ / $\mathrm{m}^{2}$ ) which is also consistent with other findings from previous studies in other countries like Saudi Arabia and Cameroon. ${ }^{14,15}$ When we categorized the physicians central obesity status the finding was alrming. Overall $88.3 \%$ physician had waist height ratio $>0.5$. The high proportions of overweight and obesity among physicians might be attributed to high consumption of fast food owing to lacking of time and sedentary life.
This study showed almost similar overall hypertension prevalence and gender distribution to the national survey. The overall reported HTN was $23.36 \%$. Nineteen percent had SBP $\geq 140 \mathrm{~mm}$ of $\mathrm{Hg}$ and $23.4 \%$ had DBP e"90 mm of Hg.. According to the WHOSTEPwise Surveillance approach in adults aged $\geq 25$ years, prevalence of hypertension was $17.9 \%$ in general, $18.5 \%$ in men and $17.3 \%$ in women in 2010 . Twenty two percent of our male physician were hypertensive (Reported or measured) versus $18 \%$ in female. Such a high prevalence of hypertension may contribute to the high prevalence of CAD in Bangladesh. The hypertension prevalence from this study was about the same as other surveys in Saudi arabian which reported increased risk of hypertension among physicians. This high prevalence of hypertension among physicians may be attributable to changes in dietary habits especially fast $\&$ salty foods, sedentary lifestyle, high job stresses and rates of obesity.

One of the surprising findings of our survey was that though overall reported DM was $13.87 \%$. Overall $27.7 \%$ physicians had $\mathrm{FBS} \geq 7 \mathrm{mmol} / \mathrm{L}$ (male $28.3 \%$ and female $26.3 \%$ ). It is much higher than the national survey findings. Exact prevalence of DM in Bangladesh is not known. According to the (NCD) Risk Factor Survey 2011 13 prevalence of self-reported or documented DM is $3.9 \%$ (men $4.3 \%$ and women $3.6 \%$ ). Our high findings might be due to higher frequencies of physical inactivity, overweight \& obesity and hypertension which wellknown risk factors are for type 2 DM. Furthermore, occupational stress is additional factor that should be taken into consideration. This explosion in diabetes prevalence will place Bangladesh among the top seven countries in terms of the number of people living with diabetes in $2030 .^{16}$

Dyslipidemia is one of the top 5 major risk factors leading to cardiovascular disease. In contrast to a previous study conducted in Brazil, ${ }^{17}$ physicians in current study had higher percentage of high total cholesterol level, high triglyceride level, low HDL-C, and high LDL-C (49.6\%, 36.5\%, 64.2\% and 46.7\%). Among the physician of Brazil the respective values were $21.4 \%, 16.6 \%, 15.5 \%$ and $13.1 \%$ respectively. However our findings were similar to the findings of SaudiArabian study. Higher prevalence of dyslipidemia among physicians in our study might be attributed to high prevalence of sedentary life, overweight and obesity \& lack of care in healthy food preparation at home, however, there were insignificant differences between the studied groups. 
Studies exclusively related to dyslipidemia are sparse in Bangladesh. In a study involving secretariat employees in Dhaka, abnormal fasting total cholesterol (TC), LDLC, HDL-C and TG were found to be $17.3 \%, 48.5 \%$, $75.6 \%$ and $48.5 \%$, respectively. ${ }^{18}$ A very recently published study ${ }^{19}$ involving 51,353 predominantly urban persons over 2005-2011, demonstrated significantly higher mean serum levels of TC, LDL-C, TG, LDL to HDL ratio and TC to HDL ratio among younger adults aged 30-39 years compared to other age groups, regardless of sex. Our study result was in agreement with this age and sex distribution with higher prevalence among physician older than forty year. Probable explanation may include rapid urbanization with less physical activities, environmental pollution, climate change, and changes in dietary habits, and also increasing access to day-to-day modern amenities leading to reduced physical activity and sedentary life styles, especially in younger adults. Despite considerable disparities in the prevalence of individual components of abnormal lipid profile, it is apparent that dyslipidemia is prevalent among the Bangladeshis in general. Studies are needed to determine the lipoprotein profile of the population for better understanding of the contribution of dyslipidemia to the etiopathogenesis of CAD.

The results of our exploratory survey should be interpreted in the light of some limitations we had. Due to exploratory nature of the survey on a convenient sample of working physicians which was small, our results can only provide a snap shot about the real scenario. Therefore, our results cannot be applied to other physician of Bangladesh. However, our study is expected to set a benchmark for further studies. As smoking behavior was self-reported there could have been reporting bias. Verification of self reported smoking behavior with nicotine tests was not possible since our survey was not funded.

\section{Conclusion:}

The present study could conclude that; the studied physicians at Chittagong Medical College \& Hospital, Bangladesh had high frequency of cardiovascular diseases risk factors including smoking, overweight or obesity, central obesity, hypertension, type 2 diabetes mellitus, and dyslipidemia. The overall 10 years and lifetime risk of ASCVD were high among them.

The findings of the analysis were in line with many studies conducted at the country level and in the region. The high prevalence of CVD risk factors among participated physicians reflected alarming public health concerns and a future health demand. It constitutes a threat if health promotion and awareness programs are not well designed. So primary prevention of CVD should be a part of occupational medical preventive examinations of both physicians and other health care professionals. Moreover, changing their attitudes towards adopting healthy life style $\&$ improving health conscious behavior are important principles for reducing these risk factors. Although NCD indicators are set, health policies are in place, clinical guidelines for major CVD risk factors are available, continuous surveillance for CVD risk factors are to be strengthened, and guidelines for CVD detection and prevention are needed. Moreover, future researches are recommended.

\section{References:}

1. World Health Organization. Cardiovascular Diseases (CVDs). Fact Sheet N 317. January 2015.

2. Hussain SM, Oldenburg B, Wang Y, Zoungas S, Tonkin AM. Assessment of Cardiovascular Disease Risk in South Asian Populations. Int J Vasc Med. 2013.

3. El-Saharty S, Ahsan KZ, Koehlmoos TL, Engelgau MM. Tackling Noncommunicable Diseases in Bangladesh: Now is the Time: Direstion in Development.Washington, DC:World Bank; Creative Commons Attribution CC BY 3.0. World Bank Publications; 2013.1$13 \mathrm{p}$.

4. Kannel WB, McGee D. Diabetes and glucose tolerance as risk factors for cardiovascular disease: the Framingham study. Diabetes Care. 1979. 2(2):120-6.

5. Whiting DR, Guariguata L, Weil C, Shaw J. IDF diabetes atlas: global estimates of the prevalence of diabetes for 2011 and 2030. Diabetes Res ClinPract. 2011. December;94(3):311-21.

6. Joshi P, Islam S, Pais P, Reddy S, Dorairaj P, Kazmi K, et al. Risk factors for early myocardial infarction in South Asians compared with individuals in other countries. JAMA. 2007. January 17;297(3):286-94.

7. Islam SR-u, Rahman F, Siddiqui MMR. Bangladesh is Experiencing Double Burden with Infectious Diseases and Non-communicable Diseases (NCD's): An Issue of Emerging Epidemics. Anwer Khan Modern Medical College Journal. 2014. 5(1):46-50.

8. WHO Tobacco Free Initiative.The Role of Health Professionals in Tobacco Controll. World Health Organization 2005.

9. Kleniewska, A., M. Ojrzanowski, A. Lipinska-Ojrzanowska, M. Wiszniewska, J. Walusiak-Skorupa, 2012. Barriers to professional activity among people with cardiovascular diseases. Med Pr 63(1): 105-15.

10. Smith, D., P. Leggat, 2011. Smoking among Healthcare Professionals.Sydney: Darlington Press.

11. S. Mendis, L. H. Lindholm, G. Mancia et al., "World HealthOrganization (WHO) and International Society of Hypertension(ISH) risk prediction charts: assessment of cardiovascular risk for prevention and control of cardiovascular 
disease in lowand middle-income countries," Journal of Hypertension, vol. 25,no. 8, pp. 1578-1582, 2007.

12. WorldHealthOrganization, WHOReport on the Global TobaccoEpidemic, 2011. Warning about the Dangers of Tobacco, WorldHealth Organization, Geneva, Switzerland, 2011.

13. World Health Organization.Non-Communicable Disease Risk Factor Survey Bangladesh 2010. [cited 2013 Jul 3].

14. Sobngwi, E., J. Mbanya, N. Unwin, T. Aspray, 2001. Albert K: Physical activity and its relationship with obesity, hypertension and diabetes in urban and rural Cameroon. Int $\mathrm{J}$ ObesRelatMetabDisord, 26: 1009-1016.

15. Mona M Aboserea, and Marwa M Zalat.Frequency of Cardiovascular Disease Risk Factors among Physicians at Jazan
King Fahd Central Hospital (KFCH), Kingdom Saudi Arabia. Research Journal of Medicine and Medical Sciences, 8(1): 1-8, 2013

16. Shaw J.E., Sicree R.A., Zimmet P.Z. Diabetes atlas: global estimates of the prevalence of diabetes for 2010 and 2030. Diabetes Res ClinPract. 2010;87:4-14. [PubMed]

17. Zemdegs, J., L. Corsi, L. Coelho, G. Pimentel, A. Hirai and A. Sachs, 2011. Lipid profile and cardiovascular risk factors among first-year Brazilian university students in São Paulo.NutrHosp, 26(3): 553-559.

18. Alam M.B., Ahsan H.A.M.N., Islam M.Z. Pattern of lipid profile and obesity among secretariat employees of Bangladesh. J Med. 2009;10:3-6.

19. Das S.K., Faruque A.S.G., Chowdhury A.K. Lipoprotein status among urban populations in Bangladesh. Atherosclerosis. 2012;223:454-457. 